\section{EMBRYARIDDLE}

Aeronautical University

SCHOLARLY COMMONS
Journal of Aviation/Aerospace

Education \& Research

Volume 17

Number 1 JAAER Fall 2007

Article 6

Fall 2007

\title{
Nonverbal Communications: A Commentary on Body Language in the Aviation Teaching Environment
}

Robert W. Kaps

John K. Voges

Follow this and additional works at: https://commons.erau.edu/jaaer

\section{Scholarly Commons Citation}

Kaps, R. W., \& Voges, J. K. (2007). Nonverbal Communications: A Commentary on Body Language in the Aviation Teaching Environment. Journal of Aviation/Aerospace Education \& Research, 17(1).

https://doi.org/10.15394/jaaer.2007.1439

This Article is brought to you for free and open access by the Journals at Scholarly Commons. It has been accepted for inclusion in Journal of Aviation/Aerospace Education \& Research by an authorized administrator of Scholarly Commons. For more information, please contact commons@erau.edu. 


\title{
NONVERBAL COMMUNICATIONS: A COMMENTARY ON BODY LANGUAGE IN THE AVLATION TEACHING ENVIRONMENT
}

\author{
Robert W. Kaps and John K. Voges
}

Some time ago, while employed in the field of labor relations, as a chief negotiator for both a major and a national airline, one of the authors wrote an article on the use of and merits of 'body language' or kinesics in the negotiation process. The substance of the message conveyed observations of common characteristics and positions displayed when different negotiating tactics are employed. More recently both authors have assumed positions in the secondary aviation teaching environment. In each of their respective roles interaction with students displays many of the characteristics of the negotiation process. From the bargaining table to the classroom, body postures bear striking resemblance in the presence of an unwritten/unspoken message. The author's opine being ignorant or failing to understand rudimentary body language cues can work against an educator's ability to convey the message he/she desires to express

The fundamental rationale behind an educational experience is the transfer of information. This paper suggests efficient and effective enhancement supports verbal communication with body language. Nonverbal behavior, on the part of the instructor and student, provides fertile ground toward effective and efficient information transference.

Body languages, facial expressions, gestures, tone of voice are all forms of nonverbal communication. So familiar are they in all aspects of social life that we often overlook their significance. In attempting to read or understand where a person or negotiator is coming from during crucial stages of intense labor negotiations, an educated theory of perception can be critical. This understanding, or perception, of the opposition's body language in the negotiation process is often the basis for decision. Bates, Johnson and Blake (1982) stated "nonverbal messages cannot be read with certainty. To suggest that they can is irresponsible, but to ignore them is equally irresponsible" (p. 129). In a highly charged environment, as the labor negotiation process, a well trained participant must rely on all tools at their disposal. To do otherwise would be feckless. Sensitivity to people's mannerisms, being able to evaluate a person's diacritic traits by studying the facial expressions, hand, and body gestures, is an invaluable skill for a negotiator. Emerson (1850) wrote: "A man passes for what he's worth. What he is engraves itself on his face, on his form, on his fortunes, in letter of light. Concealment avails him nothing, boasting nothing." Baesler and Burgoon (1987) indicate most nonverbal behavior within the areas of kinesics (the study of bodily movements), proximics (the study of special area) and haptics (the study of touch) can be measured reliably.

Experts say that a minimum of $75 \%$ of all communication is nonverbal. Birdwhistell(1981), a leading anthropologist, estimated that nonverbal behavior accounts for at least $65 \%$ of face-to-face communication. Accordingly, communication has more to do with the way we look, how we convey a message, and the way we say things, rather than the actual verbal message. Ardnt and Janney (1991) would attribute this to 'emotive communication'. Emotive communication is that which is culturally learned; cognitively mediated by use of nonpropositional signals to express feelings, manage impressions and to reach speech goals.

For many in the labor negotiation venue, kinesics weighs very heavily in the process of negotiation. The bottom line is that the better one becomes at reading and conveying nonverbal messages, the more effective one becomes as a negotiator and consequently, a communicator. So important has the area of paralinguistic become to the labor practitioner that studies and articles have been written concerning communicative aspects of body language in the labor negotiating process. Karrass (1992) extols practitioners to beware of hyperbole and concentrate on body language for the real meaning of what is being said.

So important is the non-verbal message and its 
conveyance that organized labor has routinely enrolled their negotiators in intensive body language seminars and workshops. Such importance is also conveyed by those in the field of teaching individuals an understanding of 'how to negotiate'. At the Negotiation Institute, a not for profit agency involved in the field of negotiating research their introductory brochures indicates,

Negotiating body language

is an important part of our training programs. Social cues, different stances and various poses give off important non-verbal c o m m un ic a t i o n information....Insights into non-verbal behavior will add to your negotiating strength. In our training you will learn to interpret what the other side is saying in addition to their words. At the same time you can become more aware of what your body language is saying to your opponent (p.1)

In a closely related profession, recent studies have been undertaken to determine the impact of nonverbal communication in the legal practice. Remland (1993) found research on nonverbal courtroom communication produced important findings for practitioners in five areas. In his research conclusions, Remland found that nonverbal communications impact strongly on jury analysis, client demeanor, witness cross examination, opening and closing statements, and judge's demeanor and communications. The following testimony of a man who sat on a jury is an example of how kinesics comes into play in the courtroom: "I sat on a jury that was determining the guilt or non-guilt of a person accused of theft. The arresting officer sat and glared at the accused in a most unprofessional manner through the entire trial. The case against the accused was purely circumstantial and the testimony of the arresting officer was all but disregarded, primarily due to his unprofessional body language in the courtroom. Every juror saw it. It was clear by his body language that he was out to get the man accused of the crime, and the integrity of his testimony was severely compromised. The defendant was found 'not guilty' because the case was based primarily upon the weak evidence of arresting officer's investigation. In my opinion, the case could have gone either way had it not been for the officer's blatant error of judgment in the courtroom."

When individuals speak, they do not normally confine themselves to the mere expression of sounds or utterances. Because speaking and the negotiating process involve at least two parties in sight of one another, a great deal of meaning is conveyed by facial expressions, tone of voice, movements of the body and by gestures of the hands. Mabry (1989) confirmed that kinesic limb movement, posture, eye shifts toward or away from direct eye contact, and body orientation (angle) relative to another interaction significantly changed when relating nonverbal behavioral changes to patterns of distribution of verbal interaction.

In recent years, both authors made a switch from the conference negotiating room to the academic environment. Discovering the classroom to be decidedly more reserved and oftentimes staid by comparison, they found the need for information conveyance remains a major factor. Additionally, each found little formality or format existing relative to the proper way to instruct or to instruction methodology per se. Thus, almost all format and presentation structure is left solely to devices and means of the instructor. The implication here is that a void exists not only in the continuity of training methodology, but also in the evaluation process determining the value and delivery of the curriculum. From this, one may deduce the means of interpreting whether the message, on a day to day basis, is delivered, conveyed, received and interpreted as intended. Since no formalized training exists in kinesics and its importance, except in the most advanced areas, one may draw the conclusion that many educators may be missing the mark in the area of delivery and reception.

According to Gray (1984) teachers are not trained (nor given examples or role models) in nonverbal teaching behavior and communication. In fact, teachers tend to make themselves less effective by being, often unwittingly, physically inactive and inaccessible. Inactivity and inaccessibility imply immobility, which in turn represent the teacher's lack of conscious mobility, behavior and strategies for the classroom (p. 23). If, in fact, the purpose of teaching is to imbue knowledge and issue information to classroom participants, it may be necessary to approach the classroom as a negotiator approaches a bargaining session. An educator, aware that comprehension is related to many factors, can seek broad solutions having a promise of improving comprehension levels.

How does an instructor convey the message or course content in the most effective way? How does the instructor recognize whether a positive learning process is taking place? What is the response by the participants to the instructor and/or the curriculum? Can an instructor wait until student evaluation of the instructor and course, or test results are received for analysis, before making evaluations and corrections to curricula? Some of the answers to these questions can be addressed by observation and visualization of student responses to various stimuli within control of the instructor. An instructor having an understanding of 
kinesics, as a well trained, experienced negotiator would, can make adjustments to delivery on a virtually real time basis, thereby significantly enhancing the learning environment.

Instructors should be aware of nonverbal communication in the classroom in order to enhance their ability to (a) receive students messages more accurately, (b) send congruent and positive signals to denote expectation, convey attitudes, regulate interactions and reinforce learning, and (c) avoid incongruent and negative cues that confuse students and stifle learning (Miller, 1986).

According to Weaver (1976), communication is all of the procedures by which one mind can affect another. If this is true, the instructor who fails to observe the unspoken delivery of information and interpret recipient's attitude is conveying only a small portion of the intended message. Gestures and other kinesic signals synchronized to reinforce a verbal message clarify its meaning and create a sense of the speaker's presence and purpose. Should they contradict a verbal message, confusion and doubt are introduced. Flinders (1991) indicates kinesic patterns may completely override the meaning of the spoken message. Everything a teacher does is a part of the communication process. A teacher must insure the correct message is sent by keeping to a minimum anything that conflicts with the fidelity of the intent. Effective communication is providing information and determining that this information was received and further, that the intent or meaning of the information was correctly interpreted. There is seldom if ever enough time to question each student on every issue to insure the message was properly interpreted. However, scanning the classroom during a lecture, evaluating the language of listening, makes for an effective and efficient communication technique.

During the scanning of the classroom, however, there is the danger of the instructor's enthusiasm and confidence being usurped by confusion and doubt if the focus of the instructor turns to the student who appears to be bored with the lecture. While it is true that the instructor needs to address the issues of boredom with individual students, we have found that if focus is on the student who is enthusiastic about the material being presented, then in turn, the instructor is enthusiastic about presenting the material. Hopefully, those students somewhere between the extremes of enthusiasm and boredom will become infected with a certain degree of interest. Conversely, if attention is pulled toward the apathetic individual, then the instructor's attitude will be affected, not to mention enthusiasm and confidence, and the chain reaction continues on to the would-be enthused student. From there the whole environment of the period becomes dynamically unstable, never to return to a state of equilibrium.

We have all experienced loss of interest and attention when we must listen to a teacher or lecturer who never moves from the podium, or worse, one who delivers a monatomic presentation devoid of any physical gestures. Both authors agree that one instructor stood out in the remembrance of undergraduate study. In each case the individual recalled was the one who piqued curiosity, who held their audience spellbound by the weight of oratory and sheer gesticulation. Though the precise context of the message may have faded with time, the power of the messages conveyed still remains paramount; messages whose force lies in the remembrance of the delivery, not the verbiage.

The most pivotal aspect of body language deals with the impressions the students draw from the way a teacher moves. He or she can give an air of superiority or the feeling of being approachable, open and friendly. Responsive teachers move among students, make eye contact, and smile. Unfriendly teachers are wooden, look only occasionally at the class, and appear to be unhappy or bored (Murray \& Murray, 1992). Reflective teachers (Schon, 1987) think about the worthwhileness of the educational goals they are trying to achieve, the nature and effectiveness of the instructional techniques used to reach those goals, the assumptions behind the choice of instructional means and ends, and the extent to which scientific evidence supports their choice of means and ends. Reflective teachers set aside time to think about what they do in class, why they do it, and how their methods affect student performance.

While schools have existed, students of all ages have been taught to recognize the structure and usage of language for communicating understanding between people. Unfortunately, all too often curricula concentrate on one aspect of communication, the spoken utterance, to the exclusion of nonverbal signals. Such an emphasis erroneously assumes that transmission of words and phrases are all that is important in sending a message.

The dominant source of meaning and feelings derived from a message come from the nonverbal dimension in conjunction with the verbal dimension. Not only what is said, but also what is seen. One is not mutually exclusive of the other. It is not surprising, therefore, to discover that inconsistencies between nonverbal behaviors and verbal aspects of a message reduce fidelity. When some inconsistency occurs between words and actions, we tend to believe what we infer from the nonverbal behaviors. Our messages may be misunderstood, be distorted, or lack fidelity if our nonverbal behaviors fail to support what we say.

Research demonstrates, and several articles have shown, that the nonverbal component of classroom communication is more influential than the verbal component (Keith, Tornatzky \& Pettigrew, 1974). Henney and Mortenson (1973) found that $82 \%$ of teacher's messages are nonverbal. According to Kane (1995) there are distinct 
pedagogical advantages in using body language as an effective visual aid. Birdwhistell (1970) observes that "like other events in nature, no body movement or expression is without meaning in the context in which it appears." This can be demonstrated by people who do not speak or understand your language, by babies as they respond to people around them, and even by animals. Birdwhistell also asserts that "like other aspects of human behavior, body posture, movement and facial expressions are subject to systematic analysis." Quite possibly R. D. Long's (1960) teacher lamenting his evaluation did not recognize this systematic analysis when he said, "I see myself as an interesting and enthusiastic teacher. I believe you should see me as an interesting and enthusiastic teacher. Why then do you say in your evaluation that I am an uninspiring and boring teacher?" Most of us should realize that the mere existence of inner enthusiasm in no way guarantees that students will know about it. Students do not have supernatural powers of perception; they cannot notice or respond to a teacher's internal, affective state until it achieves external embodiment. One of the important keys to carrying the inner beliefs to the outside world is the use of an expressive speaking voice and body presence.

Another consideration is that one can not control how a body language or movement is interpreted because of the individual receiver's schema. The one who is transmitting a message has no way of knowing what the receiver's experience has been with others who may have been offensive. Each of us carries with us hidden feelings from previous relationships or encounters so that two different people might respond totally differently to the same physical gesture. One student may regard a popular professor as the greatest lecturer he or she has ever experienced, and another may find the same professor repulsive. The difference may have nothing to do with the professor, but everything to do with the students' schema and past experience.

Learning outcomes of this type are not just limited to the traditional classroom setting or to the negotiating table. The learning and communications processes described so far can be found in less formal learning environments. Prime examples are the laboratories found in the flight training environment, such as the cockpit and the flight simulator. Even the ground training that is conducted is mostly done one-on-one. A significant difference here is that the instructor-student relationship is typically compressed into a one-on-one format and thereby the nonverbal cues are up close and personal. As such, possessing an educated theory of nonverbal perception becomes vital.

In flight training, much of the ground instruction discourse occurs at a desk. Eye contact and attention between the two parties is predominant throughout the lesson as opposed to being divided to an entire class. The instructor who is aware and can correctly interpret the information being returned from their "mostly silent", one person audience has a much greater probability of conveying, reinforcing or adjusting the message being sent. In this environment, the mere action of the instructor rising from that desk to portray a concept, a notion or even a procedure on the marker board will portend greater significance and demand a higher level of alertness and concentration by the listener. The requisite proximity of the two parties sitting face to face at a desk or seated shoulder to shoulder in the aircraft has profound implications to both the transmitter and the receiver. In these situations the student has little choice but to engage and be engaged by the instructor.

The learning objectives associated with the development of a psychomotor skill set share many commonalities of those desired in the traditional classroom. As such, the nonverbal communications transmitted and received by those learners are much the same. But there are differences. For example, the instructor might caution the student to watch for traffic, reference a checkpoint or simply direct them to begin turning the aircraft by the simple point of a finger or a tilt of the head. Another significant difference is that students are encouraged to watch an instructor demonstrate a procedure. By its very nature this type of performance based training requires the student to observe and then mimic. It is this replication of essential hand movements and coordination which allow the student to master control of the machine. In this way, the student is being encouraged to observe the actions of the instructor and emulate them. In this environment, an instructor less skilled in the art of that which is unsaid may pass on traits that have unintended consequences.

In the noisy environment of the flight training cockpit combined with the crammed communications of other pilots and controllers coming through the headsets, gestures sometimes become the preferred communicative venue. Many a climb, descent or requisite power change that needs timely execution is signified to the student by an associated hand movement of the instructor. No skill imparted to the student pilot is more challenging than that of learning to land an aircraft. To express this process, there is no better apparatus in the instructor's arsenal than the gesticulations used to render a mental image of the aircrafts approach, its round-out and its flare. It is not uncommon to see an instructor using his or her left hand to emulate a runway and the right hand to evoke an image of the aircraft as it makes its final approach through to touchdown. Without the visual support provided by these types of gestures the mere declaration of the process would not impart the mental imagery that is required to instill the technique. The Aviation Instructor's Handbook [AII] (1999) states that "As physical tasks and equipment become more complex, the requirement for integration of cognitive 
and physical skills increases". To meet this challenge a well equipped instructor will be the one who is far more aware of the role kinesics play in transmitting these concepts and skills.

As stated earlier, these non verbal messages can affect the student to the positive or the negative. Hopefully, gone are the days where this unspoken communiqué would come in the form of a "wap" on the student's shoulder from a rolled up sectional chart or a demeaning tone of voice that could be interpreted by the student that they have not met the prescribed practical test standards for the maneuver attempted.

For the flight student, the climactic event that accentuates this interaction occurs when the student has completed their training and it is time for evaluation and certification, the check-ride. This is a time when there is an extraordinary degree of pressure placed on the student. There is an awareness of the scrutiny that their every move and action is being observed. This can be daunting to the student. The mere fact that the student knows that they are being observed may affect the outcome of their behavior and ultimately modify their performance.

Since evaluation flights are less about instructing and more about determining knowledge and performance, the student is left to make observations and judgments as best they can. The typical student will quietly try to ascertain their "standing" by that which is both said and unsaid, ultimately using the examiners facial expressions, gestures and tone throughout the evaluation process. As such it is critical for the examining instructor to be certain they do not send any unintended nonverbal messages.

Whether the role of the instructor is to teach or to examine, it is clear that the optimum training laboratory invokes more than commands than can be annunciated or remarks that are heard. These laboratories require the practitioner to be skilled in the detection of all messages, both verbal and nonverbal, that are conveyed. This is necessary should they wish to know that the message sent was the message received.

To be sure, the art and the science of understanding bi-directional body language is critically important for those who endeavor to become flight instructors as is the case in any discipline where human interaction is required to exchange information. It is a widely accepted premise that flight instructing for most is a transitional occupation which provides a means to an end. In other words, it is a way for less experienced pilots to build flight time and move on to more lucrative pilot employment. In fact, Falkner (2000) suggests that there are very few flight instructors that enter the field of aviation training with a background in either education or psychology.

To achieve ones Certified Flight Instructor (CFI) rating, the Federal Aviation Administration (FAA) in accordance with FAR Part 61.185 mandates that an applicant must have experience in, "the fundamentals of instructing, including: (i) The learning process; (ii) Elements of effective teaching; (iii) Student evaluation and testing; (iv) Course development; (v) Lesson planning; and (vi) Classroom training techniques". The primary text used to prepare those wishing to become CFI's and acquire this knowledge mandated by the Federal Aviation Regulations (FAR) is the Aviation Instructor's Handbook (AIH). The AIH (1999) was "developed by the Flight Standards Service, Airman Testing Standards Branch in cooperation with aviation educators and industry." "This handbook also provides aviation instructors with up-to-date information on learning and teaching, and how to relate this information to the task of conveying aeronautical knowledge and skills to students (Page iii). In the opinion of the authors, this latest edition of the handbook is a vast improvement over its predecessor. Yet, interestingly there is minimal material contained in the text to address the fundamental aspect of nonverbal cognition connecting two individuals. What is included is one line in a figure that states "watch for nonverbal behavior". For many entering into the ranks of flight instruction, the only substantive formal training in nonverbal communication may have been that provided by a psychology course or less. The instructor trainee can count themselves fortunate if they have been prepped for their CFI practical examination by a veteran instructor skilled in the communicative nuances afforded by body language. Beyond this, there is little formal training on the subject that is required for certification.

In light of the usurpitous role forced on aviation and flight training on September $11^{\text {th }}$ the development of these skills go beyond being a more enlightened or effective educator. This expertise could be considered crucial. The federal government has made it a top priority to raise general security awareness levels of employees working in the flight training industry. The Transportation Security Administration (TSA) has required that all flight schools conduct mandatory Flight School Security Awareness Training (FSSA) training. This initiative of TSA is to sensitize those on the first line of defense to identify individuals who would engage in flight training for reasons of a malicious nature. This mandatory training covers many areas of security including the sensitivity of the instructor to become aware of nonverbal cues that could be considered suspect. By sensitizing those involved in pilot training the hope is to thwart would-be perpetrators intent on using aircraft for their terrorist campaigns. A main focus of the awareness training is to heighten the sensitivity of these trainers towards suspicious behavior. By learning what behaviors or activities may be considered suspicious, these instructors will become the "eyes and ears" of the transportation and aviation industry. This training includes guidance on the types of conduct to be watchful of and 
consideration given to its frequency. The observance of student activity is considered key to this training. Seeing a student who perspires abnormally, one who exhibits a high degree of nervous energy or one who becomes agitated easily are examples of behavior that could indicate something extraordinary. These actions combined with other "unusual" behavior, may be suspect and justify further examination. The point is that these covert signals are being sent and if the receiver (the instructor) is tuned in and has the skill to interpret, many of these communications can be retrieved.

Certainly, our ultimate ambition is to distill the training process to its most pure form. At a minimum, we might achieve the utmost measure of exchange between the instructor and the student. At best, we might intercept those who would wish to do us harm.

There are no universal clear cut rules for interpreting body language. Classroom teachers who recognize nonverbal signals enhance their classroom management techniques. By curbing hostile or passive gestures and movements, matching verbal and nonverbal messages, and providing reliable and effective cues to their students, a better understanding between the parties develops. Burgoon and Burk (1990) indicated that greater perceived competence and composure were associated with greater vocal and facial pleasantness, while greater facial expressiveness contributed to competence. Similarly, greater sociability and perceived persuasiveness were associated with vocal pleasantness and with more body movements and student interaction.

Two thousand years ago, the Roman orator Cicero laid down three duties for a speaker that are relevant for today's teacher. Those duties consist of: (1) to be clear, so the audience can understand what is said; (2) to be interesting, so the audience will want to listen; and (3) to be persuasive or convincing, so the audience will agree. In striving to accomplish these goals, language and actual physical delivery, the use of voice and body to communicate verbally and nonverbally, are the chief factors to consider after lesson plans are organized. Both are the means by which the full text and intent of the message can be brought to the student.

A caveat for educators concerned with message context and content is that distortions between verbal and nonverbal aspects of a message develop with inconsistencies in the delivery. Knapp (1972) has identified six ways in which nonverbal behavior support verbal comments. An educator would be well advised to consider incorporating them into the lecture repertoire as additional methodology to enforce and imbue the original message.
Nonverbal behavior may repeat what is expressed verbally.

Since nonverbal behavior, like gestures, usually precedes what is said, for example a nodding of the head when in agreement, verbal and nonverbal behaviors tend to repeat and confirm each other. Imagine the student who correctly answers a question and the teacher who affirmatively responds with a resounding 'yes' while gesturing with a high five. This response reinforces the correctness of that student's answer and the positive body motion will indelibly create a linkage for the future. A side effect of this example is directed at other students within the classroom. We all realize that an individual's attention span can be relatively short compared to the length of a class. Sitting for extended periods of time, listening to an inanimate instructor, can be exceedingly boring. An instructor moving about the classroom, making eye contact and challenging students to become aware of and alert to their surroundings destroys the stagnated atmosphere of a boring classroom. Not only do students need to listen but they also must watch what is going on around them. The point is, as an instructor moves about, next to, around and behind students, a degree of anxiety permeates the classroom. This anxiety heightens alertness, eyes open, heads turn, hearing is more acute; attention levels significantly increase.

Nonverbal behavior may contradict what is expressed verbally.

Nonverbal gestures contrary to the message being given pose the greatest threat to communication. It is important that the message and the gestures coincide for a positive association to exist. When such is not the case, the gesture will remain predominant. Pace and Faules (1986) indicate that when inconsistency occurs between words and actions, we tend to believe what we infer from the non verbal behaviors. Our message may be misunderstood, be distorted, or lack fidelity if our non verbal behaviors fail to support what we say. For example, consider the student who asks a question and the instructor, although answering the question positively, believes the timing and the question to be irrelevant, motions toward the ceiling with his eyes, indicating displeasure, or shrugs a shoulder or sighs before he replies. In this example the perceived indifference of the instructor's body language may very well have a greater effect on the student and the class than the actual positive verbal response. Even though the student received a positive verbal response the negative body language will have a greater impact on the student/class. Further, in the classroom environment it can be very difficult to achieve a meaningful dialogue. Students who observe and/or receive a negative nonverbal response will close up, and demonstrate reluctance to participate. 
Nonverbal behavior may substitute for what could be expressed verbally.

This area clearly needs no elaboration as most of us have experienced untoward messages contained in finger salutes, tongue motions and just general negative implications of circumspect body language. On the positive side, military salutes, winks and smiles can indicate acceptance and/or respect. Consider also how nonverbal behavior can assist an instructor to determine in an efficient manner whether or not the message sent is being received. There is seldom, if ever, enough time during a lecture to stop and question each student to determine if the message has been correctly interpreted. How then does an instructor know that the message is being received? Nonverbal behavior can readily provide an instructor with immediate feedback. Making eye contact, watching for nods of acceptance or the negative shake of a head, upright or slumping posture, etc., may be an indication to the degree the class and/or individual students are receptive. Here again, the instructor has to be particularly careful that the negative feedback from students (i.e. slumping posture, appearance of boredom, facial expressions of "could-notcare-less" attitude) does not affect him or her as the instructor to the point that she or he looses enthusiasm, self confidence, and mental composure, leading to the loss of physical composure - the cycle continuing in a downward spiral. This is the "desperate moment" when the instructor needs to have an alternative strategy to call upon, a survival plan to bring everybody back to Earth.

Nonverbal behavior may modify or elaborate verbal messages.

If, as stated earlier, contradiction imparts meaning to the gesture, even an ill fated message can be interpreted correctly if the nonverbal gesticulation is in support of the intended message. "I know you think you understand what I said, but I don't think you realize that what I said is not what I meant." How often have you heard one thing from someone and correctly understood the message to mean something quite different. It can be rather frightening. But it happens. Having sensitivity to nonverbal behavior can very often transcend the spoken word. Nonverbal behavior frequently communicates true meaning or intent when a contradictory message is verbalized.

Nonverbal behaviors may emphasize parts of a verbal message.

As in the above, gesticulation can support or disclaim the entire intended message or only parts of such. In such a case, as with all the above, it is incumbent on the practitioner or educator to incorporate powerful and specific cues to insure what they mean is what they get. Briefly alluded to earlier was how nonverbal behavior may punctuate the verbal message. Used properly, nonverbal behavior may readily emphasize particular points of interest. There is no need to stomp on the floor and exclaim, "This is a test question," when a more effective nonverbal technique accomplishes the same thing. Using a gesture, a timely pause and making eye contact can be far more effective and less disruptive than the foot stomping method.

Nonverbal behaviors may regulate the flow of messages between people.

A simple analogy is helpful here. Consider the conductor of an orchestra. Using predetermined signals, the maestro controls, coordinates and guides a large number of individuals through a complex series of tasks. Not a word is spoken, yet each individual is prompted to start or stop, the tempo is set and the musical piece is concluded at a precise moment. Like the conductor, an instructor's demeanor in the classroom environment is not dissimilar. Although a considerable amount of speaking is required, there is a point where teachers must contain themselves and, through nonverbal behavior, stimulate, control and moderate classroom discussion. In doing so, discussion among students and instructors is enhanced to a point where the learning experience may have a lasting effect. Students speaking to one another, regulated nonverbally by the instructor, may absorb information more thoroughly.

It would be absurd to speculate that a course could be conducted without a considerable amount of verbal discourse. Even courses for the speaking- and hearingchallenged individuals use the spoken word to communicate understanding. Nonverbal behavior will occur in all venues because it is an integral part of the communication package. Instructors are encouraged to be aware of nonverbal nuances and cues, take advantage of them and use them to regulate information transfer.

\section{Summary}

Possibly teachers will never approach the level of the negotiators eagle eye view of body language necessary in the dynamic collective bargaining process. This may be true of teachers because they lack the risk involved with negotiating failure and, thus, the imperative to use all elements at the negotiators disposal to extricate oneself from entanglements. But the responsibility to educate American youth also carries risk of failure; the risk of failing as an educator and the risk of failing to provide the highest quality education possible. Being ignorant of the nonverbal message of kinesics is like being in a foreign country and not knowing the language. You may gain an understanding of the land, the mountain ranges and vistas, but the totality of the culture is out of ones grasp. By being one dimensional one may get by, but the possibility of doing so is complex, uncertain and the results can only be ineffective. Responding only to verbal communication without observing the signs along the way, an educator may well convey the information he intends, but may, like the traveler, miss the totality of the experience for both himself and his students. 
Effective communication is a key element in an education, in a career, in life. Knowing how to give and how to get good information is a skill that must be learned and continuously practiced and refined. Degree of success is directly related to proficiency in communication. Reading and writing are affected by the physical delivery of speech. However, those who have developed the ability to deliver the spoken word, effectively punctuating with nonverbal body language, facial expressions, gestures and tone of voice, will be heard. Consequently, those listening will have a greater understanding of what was said.

If the old adage about believing nothing of what you hear and only half of what you see has any validity, the starting point of communication rests more in the delivery than the message. Actions do speak louder than words, both in the cockpit and in the classroom!t

Robert W. Kaps, Ph.D., is an associate professor of aviation management at Southern Illinois University at Carbondale where he teaches in the Aviation Management baccalaureate and the Master of Public Administration programs, with emphasis on airport administration and airline management. Prior to joining the Academy, Dr. Kaps spent over twenty-two years in the airline industry in various executive positions with both Trans World Airlines, Inc. and Ozark Air Lines and several years in the travel and tourism industry with Uniglobe Travel. He is widely published in the aviation venue and is the author of two books, Air Transport Labor Relations and Fiscal Aspects of Aviation Management.

John K. Voges is an assistant professor in the Department of Aviation Management and Flight at Southern Illinois University where he teaches in the aviation flight associates degree program. He is an ATP rated pilot and has spent over fifteen years with the program teaching primary flight training through executive transportation and airline transition training courses. 


\section{References}

Arndt, H. \& Janney, R. W. (1991, June). Verbal, prosodic, and kinesic emotive contrasts in speech. Journal of Pragmatics, Vol. 15, 6 pp. 521-549.

Baesler, J. E. \& Burgoon, J. K. (1987). Measurement and reliability of nonverbal behavior. Journal of Nonverbal Behavior, 11 4. Pp. 205-233.

Bates, M., Johnson, C., \& Blake, K. E., (1982). A manual for group counseling leaders. Denver. Love.

Birdwhistell, Ray L., quoted in Alton DeLong "Kinesics signals as utterance boundaries in pre-school children" in "Nonverbal Communication. Interaction, and Gesture, ed. Thomas A Sebeok and Jean Umikes-Sebeok (The Hague: Mouton, 1981)

Birdwhistell, Ray L. (1970). Kinesics \& Context. Philadelphia, PA; University of Pennsylvania Press.

Burgoon, J. K., Birk, T. \& Pfau, M. (1990). Nonverbal behaviors, persuasion and credibility. Human Communication Research 171 pp. 140-169.

Cicero, Marcus Tullius (106-43 BCE). M.T. Cicero de Oretore: or, his three Dialogues upon the character and qualifications of an orator; translated into English, with notes, historical and explanatory, and an introduction prefaced by William Guthrie (1708-1770).

Emerson, R. W. (1850). Representative men. The lives of great men. In Thomas Caryle (1795-1881), On heroes, hero worship and the heroic in history. Garden City, NY.: Double Day \& Company

Falkner, J. (2000). Changing the Way We Learn: Teaching CFI's To Teach [Electronic Version] AOPA Flight Training Magazine, Retrieved August 1, 2005, from http://www.aopa.org/members/fmag/article.cfm?article=3754

Federal Aviation Administration.(1999). Aviation Instructor's Handbook (FAA-H-8083- 9). Washington, DC:U.S. Government Printing Office.

Flinders, David J., (1991). Supervision as cultural inquiry. Journal of Curriculum \& Supervision, v6 n2 Winter. pp. 97-106

Gray, Judith A., (1984). A computerized technique for recording and analyzing teacher mobility, Educational Studies v10, n1, p.23.

Hanney, M. \& Mortenson, W. (1973). What makes a good elementary school teacher? Journal of Teacher Education, $24,4$. Pp 312-317.

Kane, L. (1995, March). Making a drama out of a crisis: Ideas for team teaching. Language Learning Journal, 11. Pp. 34-35.

Karrass, D. (1992). Body language: Beware of the hype (in the context of negotiations). Traffic Management 31. P.27. Keith, L. T., Tornatzky, L. G. \& Pettigrew, L. E., (1974). An analysis of verbal \& nonverbal classroom teaching behavior. Journal of Experimental Education, 42, pp. 30-38.

Knapp, Mark L., (1972). Nonverbal communication in human interaction. New York: Holt, Rinehart \& Winston.

Long, R. D. (1960). The divided self. London: Tavistok.

Mabry, E. A. (1989). Developmental aspects of nonverbal behavior in small group settings. Small Group Behavior 20, $2 \mathrm{pp}$. 190-202.

Miller, P. W., (1986). Nonverbal communication (2nd ed.). Washington, D.C.: National Education Association. 
Murray, John P. \& Murray, Judy I., (1992). How do I lecture thee? College Teaching v40, n3, Summer. pp. 109-113. Negotiation Institute (2004). Negotiating Body Language. Retrieved December 12, 2005 from http://www.negotiation.com/negotiating-body-language.html

Pace, R. Wayne \& Faules, Don F. (1983).. Organizational Communication 2nd. ed. Englewood Cliffs, NJ. Prentice Hall p. 153.

Remland, M. S. (1993). The Importance of Nonverbal Communication in the Courtroom. Eric Document ED378612,

Schon, D. A., (1987). Educating the reflective practitioner. San Francisco: Jossey-Bass.

Weaver. R. L. (1976). Biography of sources for (verbal \& nonverbal) activities. East Lansing, MI: National center for Research on Teacher Learning (ERIC Document Reproduction Service No. ED137869). 